\title{
The Overexpression of T $\beta 4$ in the Hair Follicle Tissue of Alpas Cashmere Goats Increases Cashmere Yield and Promotes Hair Follicle Development
}

\author{
Bai Dai $^{\dagger}$, Hao Liang ${ }^{\dagger}$, Dong-dong Guo, Zhao-wei Bi, Jian-long Yuan, Yong Jin, Lei Huan, \\ Xu-dong Guo ${ }^{D}$, Ming Cang and Dong-jun Liu*
}

State Key Laboratory of Reproductive Regulation and Breeding of Grassland Livestock, School of Life Sciences, Inner Mongolia University, Hohhot 010070, China; daibai007@sina.com (B.D.); lianghao@imu.edu.cn (H.L.); 18847763789@sina.cn (D.-d.G.); lianmengnianhua@126.com (Z.-w.B.); 15904883238@163.com (J.-1.Y.); jin_519@163.com (Y.J.); huanlei320@163.com (L.H.); xudguo@163.com (X.-d.G.); cangming@imu.edu.cn (M.C.)

* Correspondence: nmliudongjun@126.com; Tel.: +86-0471-4995071

+ These authors contributed equally to this work.

Received: 28 September 2019; Accepted: 27 December 2019; Published: 31 December 2019

check for updates

Simple Summary: Cashmere goats have double coats consisting of non-modulated fine inner hairs or cashmere fibers produced by secondary hair follicles (SHFs) and guard hairs produced by primary hair follicles (PHFs). Cashmere is an important economic product worldwide. The world market for cashmere is increasing while the current production of cashmere is limited. Thymosin beta- 4 (Tß4), a $4.9 \mathrm{kDa}$ protein, contains 43 amino acids. Here, we investigated whether T $\beta 4$ overexpression would increase SHF numbers, and thus improve the cashmere yield. We produced T $\beta 4$ transgenic goats using a tissue-specific overexpression strategy. The T $\beta 4$ overexpression (T $\beta 4-\mathrm{OE}$ ) goats had increased hair follicle development and higher cashmere yields than the wild type (WT) goats. The development of this goat model is not only valuable as a framework for future studies of the mechanism of goat follicular development, but will also lead to the improvement of economically important cashmere traits.

\begin{abstract}
Increased cashmere yield and improved quality are some goals of cashmere goat breeding. Thymosin beta-4 (T $\beta 4$ ) plays a key role in the growth and development of hair follicles. For the past ten years, we have evaluated the role of $\mathrm{T} \beta 4$ by establishing a flock of 15 cashmere goats that specifically overexpress the T $\beta 4$ gene in the hair follicles. These T $\beta 4$ overexpression (T $\beta 4-\mathrm{OE})$ cashmere goats had more secondary hair follicles than the WT goats and produced more cashmere. Meanwhile, combined analysis of the skin transcriptome and proteome in cashmere goats suggested that T $\beta 4$ may affect hair growth by interacting with keratin type II cytoskeletal 4 epidermal (KRT4) to mediate the extracellular signal-regulated protein kinase (ERK) signaling pathway, thereby promoting the development of secondary hair follicles, and consequently, increasing cashmere yield. Thus, the specific overexpression of T $\beta 4$ in the hair follicles of cashmere goats effectively increased the cashmere yield.
\end{abstract}

Keywords: T $\beta 4$; secondary hair follicle; cashmere goat; SCNT

\section{Introduction}

The cashmere goat is one of the most important genetic resources in China [1-3]. Alpas cashmere goats live on the Inner Mongolian Plateau, which is characterized by its fragile ecological conditions, intense temperature changes, sparse vegetation, sandy soils, and high winds [4]. After decades of artificial selection, cashmere goats have become the primary goat breed used for the production of 
cashmere [5,6]. Cashmere, which has become internationally known as soft gold, is an important textile with high economic value $[7,8]$. Thus, much effort has been directed toward the development of a new cashmere goat breed that can produce higher yields of finer cashmere [9-12].

Cashmere is derived from secondary hair follicles (SHFs), which are morphologically distinct from primary hair follicles (PHFs) [13]. In contrast to the PHFs (which produce guard hairs), SHFs do not contain medulla, thereby generating fibers that are soft and delicate [14]. Cashmere goat hair follicles (HFs) exhibit an annual periodicity, having three distinct physical phases per year: anagen (growth; August to October), catagen (regression; after December), and telogen (rest; after February). Cashmere production depends primarily on the area and length of the cashmere fibers. These parameters are determined by the number of SHFs and the point in the hair growth cycle at which the fibers are collected [15-18]. Indeed, one of the key goals of cashmere goat breeding is to increase the number of SHFs carried by the goat.

Thymosin beta-4 (T $\beta 4)$, a $4.9 \mathrm{kDa}$, pleiotropic, actin-sequestering polypeptide containing 43 amino acids, is associated with various functions, such as cell movement, angiogenesis, wound healing, inflammation, and anti-apoptosis [19-21]. As a primary G-actin-sequestering peptide, T $\beta 4$ plays a key role in the protection, regeneration, and remodeling of injured or damaged tissues. In rats and mice, $\mathrm{T} \beta 4$ promotes the migration of stem cells downward from the bulge region and its immediate progeny, thereby promoting hair growth [22]. Previously, when investigating the effects of endogenous T $\beta 4$ on hair growth in mice, we found that $\mathrm{T} \beta 4$ appeared to regulate proliferation-related signaling by influencing vascular endothelial growth factor (VEGF) expression, thereby increasing the speed of hair growth $[23,24]$. It is, therefore, possible that $\mathrm{T} \beta 4$ overexpression might increase the HF number in cashmere goats, subsequently increasing cashmere production.

In addition to traditional breeding methods, more efficient transgenic technologies have recently become widely used to generate transgenic animals. Somatic cell nuclear transfer (SCNT) can be used to produce a large number of embryos from genetically elite animals $[25,26]$. Reproductive cloning by SCNT using genetically-modified donor cells is a valuable method to propagate animals with desirable traits $[9,10,27,28]$. Meanwhile, SCNT technology holds great potential for stem cell biology and human therapeutics [29]. This mature technology has been successfully applied to 23 mammalian species [30], including sheep, mice, cattle, pigs, cats, rats, and dogs.

In this study, we aimed to use SCNT to generate HF tissue-specific activated T $\beta 4$ overexpression (T $\beta 4-\mathrm{OE}$ ) goats and to explore whether the T $\beta 4$ could be used to regulate hair follicle growth and development in cashmere goats. Our overarching goal was to develop a framework for the generation of genetically uniform T $\beta 4$-OE goats, which could then be used as the basis for a program dedicated to breeding cashmere goats that produce high yields of high-quality cashmere.

\section{Materials and Methods}

\subsection{Animals}

All experiments followed the National Research Council Guide for the Care and Use of Laboratory Animals (SYXK 2014-0002). All protocols were approved by the Institutional Animal Care and Use Committee of Inner Mongolia University. All goats were kept at the Inner Mongolia YiWei White Cashmere Goat Limited Liability Company.

\subsection{Design and Construction of the Vectors}

The goat T $\beta 4$ coding sequence was cloned from goat cDNA (NM_001002885). To construct the target vector, the goat T $\beta 4$ coding sequence was ligated with the KAP6.1 promoter. The KAP6.1-T $\beta 4$ fragment was then cloned into the pCDsRed2-1 vector using T4 DNA ligase (TaKaRa Bio, Shiga, Japan). The resulting T $\beta 4-\mathrm{OE}$ vector was digested and linearized with SacI (Thermo Fisher Scientific, Munich, Germany). 


\subsection{Cell Culture, Transfection, and Selection}

To improve the cloning efficiency, we chose goat fibroblasts (GFbs) isolated from both 35-day-old male and female fetal Alpas cashmere goats as donor cells [31]. We then transfected $\sim 105 \mathrm{GFbs}$ with $3 \mu \mathrm{g}$ of the T $\beta 4-\mathrm{OE}$ vector. The GFbs were subsequently screened with $800 \mu \mathrm{g} / \mathrm{mL}$ G418 (Hyclone, Munich, Germany) for 12 days. Individual colonies were identified by sequencing the PCR products covering the target loci.

\subsection{Karyotype Analysis}

We selected one of T $\beta 4-\mathrm{OE}$ cell lines and one of WT cell lines for the karyotype analysis. We began with a short-term culture of cells derived from each specimen. After a period of cell growth and multiplication, the dividing cells were arrested during metaphase by adding of $0.1 \mu \mathrm{g} / \mathrm{mL}$ colchicine and incubating for $4 \mathrm{~h}$ at $37^{\circ} \mathrm{C}$ in $5 \% \mathrm{CO}_{2}$ with saturated humidity. Arrested cells were treated with $0.5 \mathrm{~mL} \mathrm{KCl}$. The nuclei were then treated with $5 \mathrm{~mL}$ of a chemical fixative for $20 \mathrm{~min}$, dropped on a glass slide, and treated with a Giemsa stain for $30 \mathrm{~min}$.

\subsection{Cell Growth Curves}

We measured the growth of the resulting polyclonal cells by seeding the cells in 24-well plates at a density of $1 \times 10^{4}$ cells/well. Cells were counted every $24 \mathrm{~h}$ using a hemocytometer (Qiujing Co., Shanghai, China) for 8 days. Three wells were counted and averaged at each time point; these means were then plotted to calculate the cell growth curve [32].

\subsection{Generation of Cloned Goats via SCNT}

SCNT was performed as described previously [31]. Briefly, oocytes used for SCNT were isolated from goat ovaries collected at a local slaughterhouse (Inner Mongolia YiWei White Cashmere Goat Limited Liability Company Breeding Farm at Ulan Town of Erdos in Inner Mongolia Autonomous Region, China) and cultured by in vitro maturation for 18 to $20 \mathrm{~h}$. The mature oocytes were enucleated, and select polyclonal and WT donor cells were injected into the perivitelline space. The oocyte-donor cell pairs were fused by electric shock. The couplets were fused with two DC pulses of $190 \mathrm{~V} / \mathrm{mm}$ for $20 \mu \mathrm{s}$ each, $100 \mathrm{~ms}$ apart. The fused embryos were activated in a SOFaa activation solution containing $2 \mu \mathrm{M}$ IA23187, and cultured in SOFaa medium containing $2 \mathrm{mM}$ 6-DMAP for $4 \mathrm{~h}$ [33]. Finally, these embryos were cultured in an embryonic development medium at $38.5^{\circ} \mathrm{C}$ for 48 to $50 \mathrm{~h}$. When the embryos had reached the two-to-eight-cell stage, they were transplanted into the oviduct of a recipient and 2-5 embryos were transferred per recipient. We examined the surrogates using ultrasound (Kaixin Co., Xuzhou, China) 90-100 days after embryo transfer to identify the successful pregnancies. All cloned transgenic kids were delivered by natural birth after approximately 150 days of pregnancy. Images of red fluorescent protein expression in the goats were obtained in the dark using portable ultraviolet (UV) light and a digital camera (EOS 600D; Canon, Japan).

\subsection{PCR Analysis}

We genotyped the cells with PCR, using primers designed to identify the integration of the exogenous gene into T $\beta 4-\mathrm{OE}$ polyclonal cells (Table S1). All PCR conditions are given in Table S1. PCR amplicons were analyzed using $1 \%$ agarose gel electrophoresis and purified using the GeneJET Gel Extraction Kit (Thermo Fisher Scientific, Munich, Germany). Purified amplicons were subcloned into pMD19-T vectors (TaKaRa Bio, Shiga, Japan), following the manufacturer's instructions. Positive clones were selected and sequenced.

\subsection{Southern Blot Analysis}

We assessed the T $\beta 4$ gene expression in GFbs (isolated from two T $\beta 4+$ goats, two T $\beta 4$ - goats, and a WT goat) using a Detection Starter Kit II (Roche, Mannheim, Germany), with the WT goat 
as the blank control, following the manufacturer's instructions. In brief, we synthesized a DIG probe by incorporating Digoxigenin-11-dUTP using PCR. The forward and the reverse primers were 5' ATTGAAGAAAACGGAAACGC $3^{\prime}$ and 5'GGAACTGGGGGGACAGGATG3' , respectively. The PCR conditions were as follows: $95^{\circ} \mathrm{C}$ for $5 \mathrm{~min} ; 35$ cycles of $95^{\circ} \mathrm{C}$ for $48 \mathrm{~s}, 60^{\circ} \mathrm{C}$ for $30 \mathrm{~s}$, and $72{ }^{\circ} \mathrm{C}$ for $40 \mathrm{~s}$, and a final extension at $72^{\circ} \mathrm{C}$ for $8 \mathrm{~min}$. We then digested $20 \mu \mathrm{g}$ of goat genomic DNA overnight with Xbal I. After digestion, the DNA was hybridized with the DIG probe and measured using a chemiluminescent system.

\subsection{DNA Extraction and $q R T-P C R$}

The genomic goat DNA samples used for the qRT-PCR analysis were extracted and purified using a DNA extraction kit (Promega, Madison, USA). qPCR was performed using SYBR Premix Ex Taq II (TaKaRa Bio, Shiga, Japan) on a 7500 Real-Time PCR System (Applied Biosystems, Munich, Germany) with the following cycling protocol: $95^{\circ} \mathrm{C}$ for $30 \mathrm{~s} ; 40$ cycles of $95^{\circ} \mathrm{C}$ for $5 \mathrm{~s}$ and $60^{\circ} \mathrm{C}$ for $31 \mathrm{~s} ; 95^{\circ} \mathrm{C}$ for $15 \mathrm{~s} ; 60^{\circ} \mathrm{C}$ for $1 \mathrm{~min}$; and $95^{\circ} \mathrm{C}$ for $15 \mathrm{~s}$. qPCR results were analyzed with qTOWER2-0. Glucagon was used as the reference gene.

\subsection{RNA Extraction and $q R T-P C R$}

Total RNA was isolated from goat skin tissue samples with RNAiso Plus* (TaKaRa Bio, Shiga, Japan). cDNA was synthesized from $1 \mu \mathrm{g}$ of the total RNA with a PrimeScript RT reagent Kit with gDNA Eraser (Perfect Real Time) (TaKaRa Bio, Shiga, Japan) in a $20 \mu \mathrm{L}$ reaction volume, following the manufacturer's instructions. qPCR was performed using SYBR Premix Ex Taq II (TaKaRa Bio, Shiga, Japan) on a 7500 Real-Time PCR System (Applied Biosystems, Munich, Germany) with the following cycling protocol: $95^{\circ} \mathrm{C}$ for $30 \mathrm{~s} ; 40$ cycles of $95^{\circ} \mathrm{C}$ for $5 \mathrm{~s}, 60^{\circ} \mathrm{C}$ for $34 \mathrm{~s}$, and $95^{\circ} \mathrm{C}$ for $15 \mathrm{~s} ; 60^{\circ} \mathrm{C}$ for 1 min; $95^{\circ} \mathrm{C}$ for $30 \mathrm{~s}$; and $60^{\circ} \mathrm{C}$ for $15 \mathrm{~s}$. The relative gene expression was calculated using the $2^{-\Delta \Delta \mathrm{Ct}}$ method, with GAPDH as the reference gene (see Table S2 for the primers used).

\subsection{Western Blot Analysis}

Skin tissue samples were obtained as described above and prepared for SDS-PAGE. The total proteins were separated using SDS-PAGE and then electroblotted onto a polyvinylidene difluoride membrane. After blocking in 5\% non-fat milk for $1 \mathrm{~h}$ at room temperature, the membranes were incubated overnight at $4{ }^{\circ} \mathrm{C}$ with primary antibodies (1:1000 dilution; Abcam, Cambridge, $\mathrm{UK})$. After incubation, the membrane was rinsed sequentially with phosphate-buffered saline and phosphate-buffered saline containing $0.05 \%$ Tween- 20 solution. Subsequently, the membrane was treated with secondary antibody. (1:1000 dilution; Abcam, Cambridge, UK). The protein bands were visualized with a Pierce ECL western blotting substrate (Thermo Fisher Scientific, Munich, Germany), using the Tanon 5200 (Tanon, Shanghai, China) detection system. GAPDH was used as the loading control [31,34].

\subsection{Hematoxylin-Eosin (HEE) Staining}

Skin tissues obtained from cloned goats and wild-type goats of the same age were prefixed with $4 \%$ paraformaldehyde for $48 \mathrm{~h}$, dehydrated in a series of alcohol concentrations, transferred into xylene, and embedded in paraffin. We cut $5 \mathrm{~mm}$ sections from each embedded tissue sample, and stained the sections with H\&E. Stained sections were dehydrated and sealed with a cover slip.

\subsection{RNA Sequencing Alignment and Transcriptomic Analysis}

Skin tissue samples were obtained from the backs and abdomens of T $\beta 4-\mathrm{OE}$ and WT goats and stored in liquid nitrogen. Each sample was ground in liquid nitrogen, and the total RNA was extracted using RNAiso Plus* (TaKaRa Bio, Shiga, Japan), following the manufacturer's instructions. RNA 
integrity and purity were assessed using an Agilent 2100 Bioanalyzer (Agilent Technologies, Santa Clara, CA, USA).

We generated sequencing reads of $12 \mathrm{mRNA}$ libraries on a HiSeq $\times 10$ platform (Illumina, San Diego, CA, USA). After removing reads with $>5 \%$ uncertain bases, $>5$ bp of adaptor sequences, or $>15 \%$ low quality bases (Q-score $\leq 19$ ), we retained $>6 \mathrm{~Gb}$ of clean data for each sample. The reads were aligned using Bowtie2 v2.2.3 [35] based on the Capra_hircus_ARS1 reference genome from the NCBI database (ftp://ftp.ncbi.nlm.nih.gov/genomes/all/GCF/001/704/415/GCF_001704415.1_ARS1/ GCF_001704415.1_ARS1_genomic.fna.gz). We successfully aligned $88.89-98.13 \%$ of the paired reads with the concordant alignments to the reference genome.

The expected fragments per kilobase of transcript sequence, per million base pairs sequenced (FPKM) for each gene was calculated to estimate the expression, and DESeq2 v1.6.3 [36] was used to identify the differentially expressed genes (DEGs); the genes were considered differentially expressed when $\mathrm{q} \leq 0.05$ and $\mid \log 2$ ratio $\mid \geq 1$.

\subsection{Co-Immunoprecipitation (Co-IP)}

Co-immunoprecipitation was performed according to the instructions of the Millipore Catch and Release kit. Briefly, samples containing 1-3 mg total protein were precleared with Protein A/G Sepharose for $30 \mathrm{~min}$. The cleared lysates were incubated with $4 \mathrm{mg}$ anti-T $\beta 4$ at $4{ }^{\circ} \mathrm{C}$ for at least $2 \mathrm{~h}$, and up to overnight [37].

\subsection{Protein Mass Spectrometry (MS) Analysis}

The Co-IP product of T $\beta 4$ was used for SDS-PAGE. Normal IgG was used as the control. Following Coomassie brilliant blue staining, the SDS-PAGE bands were compared, and the bands that exhibited changes following MS (performed by BGI, Beijing, China) were excised [38].

\subsection{Cell Proliferation Assay}

Cells were incubated with an EdU reagent (Ribobio, Guangzhou, China) at $48 \mathrm{~h}$ post-transfection, and a permeabilization buffer was added $24 \mathrm{~h}$ later. The cells were then washed with PBS. After staining with Apollo solution (Ribobio, Guangzhou, China) for $30 \mathrm{~min}$, the cells were observed using fluorescence microscopy.

\subsection{Animal Management and Measurements}

According to the feeding standards of large experimental mammals, we managed the cashmere goats and regularly monitored their quality. The body weight of each T $\beta 4-\mathrm{OE}$ goat was determined at birth, with WT goats of the same age serving as controls. Body weight, cashmere clean weight, cashmere thickness, and fiber length, were monitored yearly until the goat died.

\section{Results}

\subsection{Generation of T $\beta 4-O E$ Alpas Cashmere Goats}

We used transgenic cells for producing cashmere goats that specifically overexpressed the $T \beta 4$ gene in their hair follicles (Figure 1a). First, we constructed a T $\beta 4$ expression vector (pCDsR-KT) carrying the goat cDNA for both T $\beta 4$ (driven by the hair follicle-specific KAP6.1 promoter, which targets both the primary and secondary hair follicles) and the red florescent gene DsRed2 (driven by the cytomegalovirus promoter). This expression vector was transfected into goat fetal fibroblasts (GFbs) derived from 35-day-old male and female fetuses via lipofection. After incubation with G418, 249 (M: 63; F: 186) cell clones remained. We then expanded groups of 15-20 cell clones to form 12 polyclonal cells, which exhibited normal karyotypes and growth (Figure 1b). After propagation and genotyping of the T $\beta 4$-OE polyclonal cells, we found that four polyclonal cell genomes (33.33\%) had integrated the pCDsR-KT vector (Figure 1c). 
Second, four T $\beta 4-\mathrm{OE}$ polyclonal cells and three wild-type (WT) cell clones were chosen as donors for the SCNT (Figure 1d). We compared embryos cloned from the T $\beta 4$-OE polyclonal cells and the WT cells at various developmental stages (Figure 1e) (Table S3). Cloned embryos from the four T $\beta 4-\mathrm{OE}$ polyclonal cells were transferred into 241 surrogates. Ultrasonography, 90-100 days after embryo transfer, indicated that 19 surrogates had become pregnant. Four of these surrogate embryos developed to term. In 2010, the 15 successful surrogate mothers gave birth to fifteen T $\beta 4-O E$ kids (seven males and eight females; Tables S4-S7). All kids presented with the expected red lips and hooves (Figure 2a). Cloned WT embryos were then transferred into 56 surrogates. Ultrasonography, 90-100 days after the embryo transfer, indicated that eight surrogates had become pregnant, and three of the surrogates' embryos developed to term. In 2010, five surrogate mothers gave birth to five WT kids (three males and two females; Table 1; Tables S8-S11).

Third, we monitored the body weights of all cloned cashmere goats for 6 years (Figure $2 b$ ); these body weights were not significantly different between the T $\beta 4-\mathrm{OE}$ and WT goats $(p>0.05)$.

a

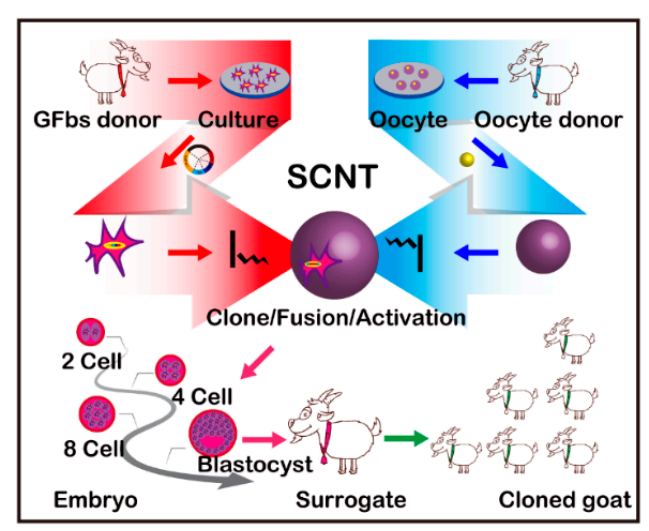

C
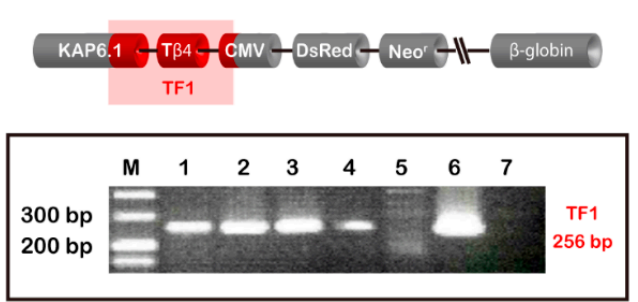

e

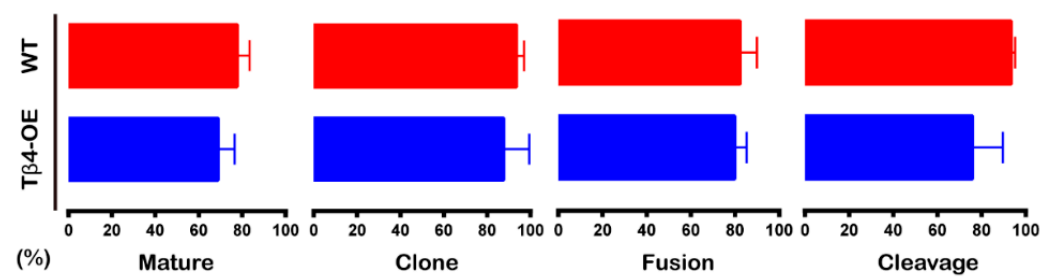

Figure 1. Generation of T $\beta 4$-overexpression (T $\beta 4-\mathrm{OE}$ ) Alpas cashmere goats. (a) Schematic of the procedure used to produce T $\beta 4$-OE goats via somatic cell nuclear transfer (SCNT). (b) Morphology, karyotype, and growth of WT and T $\beta 4-\mathrm{OE}$ goat fibroblasts (GFbs). (c) Genotype identification of WT and T $\beta 4$-OE GFbs. Lane M, DL500 DNA marker; Lanes 1-4, PCR amplicons of the T $\beta 4$ gene from the four transgenic GFbs; Lane 5, PCR amplicons of the T $\beta 4$ gene from the GFbs; Lane 6, PCR amplicons of the $T \beta 4$ gene from the $\mathrm{pCDsR-KT} \mathrm{expression} \mathrm{vector;} \mathrm{Lane} \mathrm{7,} \mathrm{PCR} \mathrm{amplicons} \mathrm{of} \mathrm{the} \mathrm{T \beta 4} \mathrm{gene} \mathrm{from}$ the blank control. (d) The T $\beta 4-\mathrm{OE}$ cloned embryos at various developmental stages. White arrow: blastocyst. Scale bar: $100 \mu \mathrm{m}$. (e) Comparison between T $\beta 4-\mathrm{OE}$ (red) and wild type (WT) (blue) cloned embryos at various developmental stages. 
a
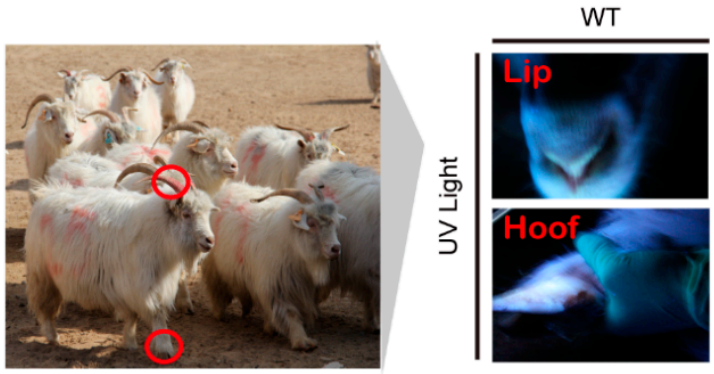

b
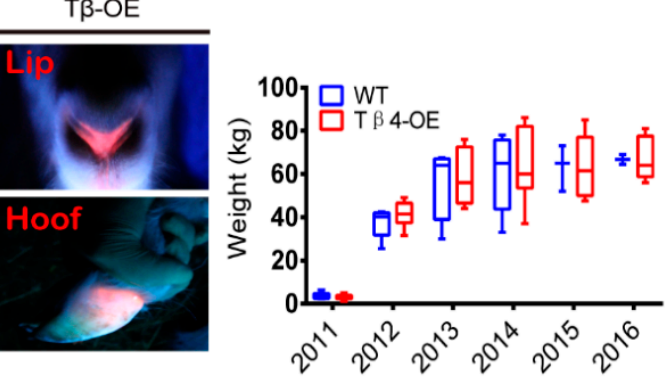

c
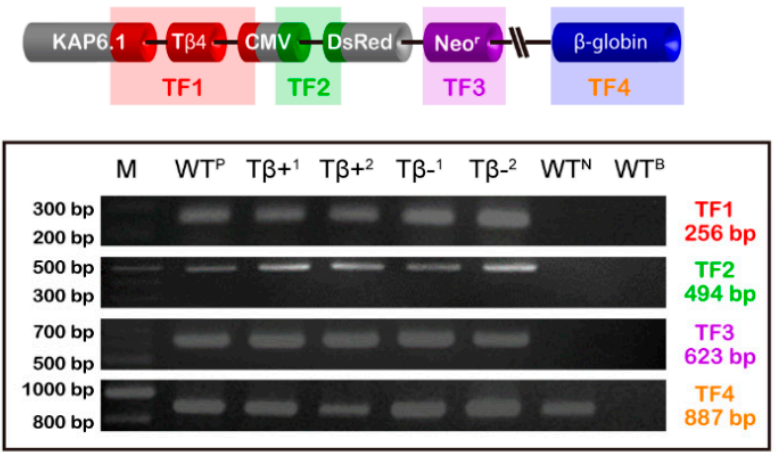

d
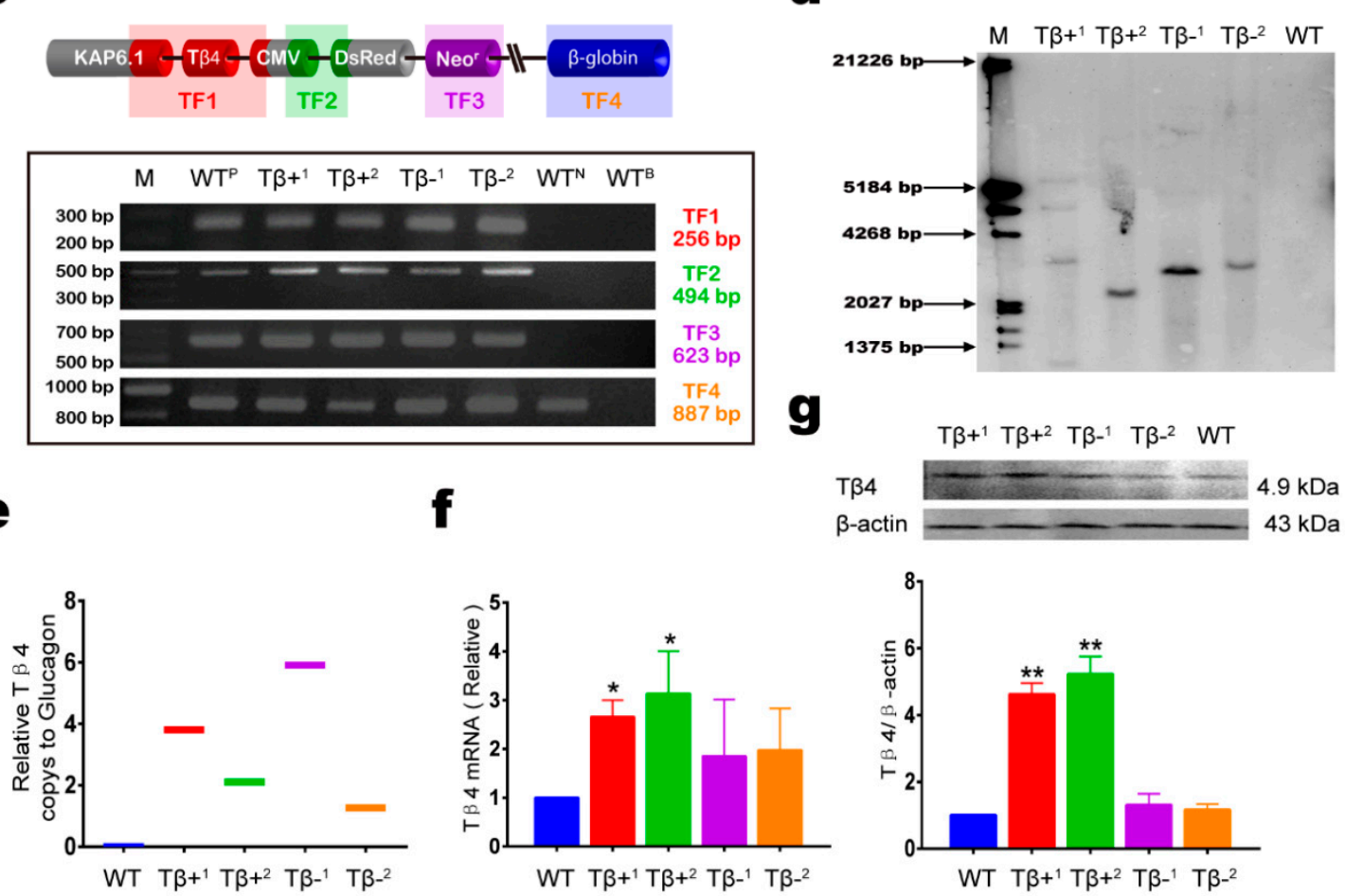

Figure 2. Identification of $\mathrm{T} \beta 4$ overexpression (T $\beta 4-\mathrm{OE}$ ) Alpas Cashmere goats. (a) $\mathrm{T} \beta 4-\mathrm{OE}$ cashmere goat, showing characteristic red lips and hooves. (b) Body weight of wild type (WT, $n=8)$ and T $\beta 4-\mathrm{OE}$ $(n=23)$ goats from at birth to six years old. Blue boxes are controls; red boxes are T $\beta 4$-OE goats produced via SCNT. (c) $\mathrm{PCR}$ analysis showing $T \beta 4$ gene insertion. $\mathrm{WT}^{\mathrm{P}}$, positive control; $\mathrm{WT}^{\mathrm{N}}$, negative control; $\mathrm{WT}^{\mathrm{B}}$, blank control. (d) Southern blot and (e) absolute quantitative PCR showing T $\beta 4$ copies numbers. (f) qPCR and (g) western blot showing T $\beta 4$ expression in WT and T $\beta 4-\mathrm{OE}$ hair follicles to assess the expression of $\mathrm{T} \beta 4$. Asterisks indicate that mean expression was significantly different from the control $\left({ }^{*} p<0.05 ; * * p 0.01\right)$. Bars indicate the means of the three replicates; error bars indicate the standard errors of the means.

Table 1. Goat birth statistics.

\begin{tabular}{cccccccccc}
\hline Group & $\begin{array}{c}\text { SCNT } \\
\text { Embryos } \\
\text { (n) }\end{array}$ & $\begin{array}{c}\text { Embryos } \\
\text { Transferred } \\
\text { (n) }\end{array}$ & $\begin{array}{c}\text { Surrogates } \\
\text { (n) }\end{array}$ & $\begin{array}{c}\text { Pregnancies } \\
\text { (n) }\end{array}$ & $\begin{array}{c}\text { The Rate of } \\
\text { Pregnancy } \\
(\%)\end{array}$ & $\begin{array}{c}\text { The } \\
\text { Number of } \\
\text { Birth (n) }\end{array}$ & $\begin{array}{c}\text { The Male (o) } \\
\text { Ratio (\%) }\end{array}$ & $\begin{array}{c}\text { The Female } \\
(\mathbf{8}) \text { Ratio (\%) }\end{array}$ & $\begin{array}{c}\text { The Rate of } \\
\text { Cloning } \\
\text { Efficiency (\%) }\end{array}$ \\
\hline WT & 360 & 360 & 56 & 8 & 14.2 & 5 & 60.0 & 40.0 \\
T $34-\mathrm{OE}$ & 1155 & 1137 & 241 & 19 & 8.9 & 15 & 46.7 & 53.3 & 1.39 \\
\hline
\end{tabular}

\subsection{Ectopic Expression of T $\beta 4$ in T $\beta 4-O E$ Alpas Cashmere Goats}

$\mathrm{T} \beta 4$ is expressed in the hair follicles throughout the adult life of the goat. We next investigated whether $\mathrm{T} \beta 4$ was overexpressed in the hair follicles of the T $\beta 4$-OE goats by comparing the T $\beta 4$ gene expression and genotypes among two T $\beta 4$-OE cashmere goats with significantly improved cashmere 
yield (T $\beta 4+)$, two T $\beta 4-\mathrm{OE}$ cashmere goats with no significant increase in cashmere yield (T $\beta 4-)$, and a wild type cashmere goat (WT). Genotyping indicated that all T $\beta 4-\mathrm{OE}$ goat genomes had integrated the pCDsR-KT vector (Figure 2c). Southern blotting and absolute quantitative PCR showed that all T $\beta 4-\mathrm{OE}$ goats carried more $T \beta 4$ copy numbers than the WT goat (Figure $2 \mathrm{~d}, \mathrm{e}$ ). However, our quantitative PCR (qPCR) and western blot analyses indicated that the T $\beta 4$ protein and mRNA expression levels were higher in the T $\beta 4+$ goats compared to the WT goats, but these levels for the T $\beta 4^{-}$goats were not significantly higher than those of the WT goats (Figure $2 \mathrm{f}, \mathrm{g}$ ). In addition, we also performed immunofluorescence testing on the samples. In T $\beta 4+$, there was more $\mathrm{T} \beta 4$ expression in the hair follicles than in WT. In the WT and T $\beta 4^{-}$goats, there was little difference in T $\beta 4$ expression in the hair follicles (HFs) (Figure S1). We compared T $\beta 4$-labeled fluorescent cell numbers between the WT cell lines and the GFbs lines that we isolated and established. We identified 2.1-fold more T $\beta 4$-labeled fluorescent cells in the T $\beta 4-\mathrm{OE}$ cell lines compared to the WT cell lines (a 2.1-fold increase; Figure S2).

\subsection{Cashmere Yield and SHF/PHF Ratio Increased in T $\beta 4-O E$ Alpas Cashmere Goats}

Unlike other breeds of cashmere goats, the hair follicles of Alpas cashmere goats are typically composed of three primary hair follicles and several secondary hair follicles (Figure 3a). Cashmere clean weight, thickness, and fiber length collectively indicate cashmere yield. We thus investigated the effects of ectopic T $\beta 4$ expression on hair follicle tissues by measuring these indicators. Although yearly cashmere yields differed among individual goats, the average cashmere yield per goat across the $15 \mathrm{~T} \beta 4-\mathrm{OE}$ goats was generally higher than that of the four WT goats (an $\approx 100-150 \mathrm{~g}$ increase). Specifically, the average yearly cashmere yield of the $\mathrm{T} \beta+$ goats was significantly greater than that of the WT goats $(p<0.01)$, while the average yearly cashmere yield per T $\beta 4$ - goat was not significantly different from that of the WT goats $(p>0.05)$. No significant differences in cashmere thickness or fiber length were found between any T $\beta 4-\mathrm{OE}$ and WT goats (Figure $3 b, c)$. To investigate the difference in cashmere yield among the T $\beta 4+, \mathrm{T} \beta 4-$, and WT goats, we analyzed the hair follicles of goats from the three groups. Hematoxylin-eosin (H\&E) staining of the back and scapula skin tissues of all goats showed that the average SHF/PHF ratio of the T $\beta 4+$ goats was significantly greater than the average SHF/PHF ratios in the WT and T $\beta 4$ - goats (Figure $3 \mathrm{~d}$ ). Statistical analysis showed that $\mathrm{T} \beta 4$ expression levels in the hair follicle tissues were significantly correlated with cashmere clean weight $(p<0.01)$ and SHF/PHF ratio $(p<0.01)$ but were not significantly correlated with cashmere thickness or fiber length $(p>0.05$ Figure $3 \mathbf{e})$. 
a

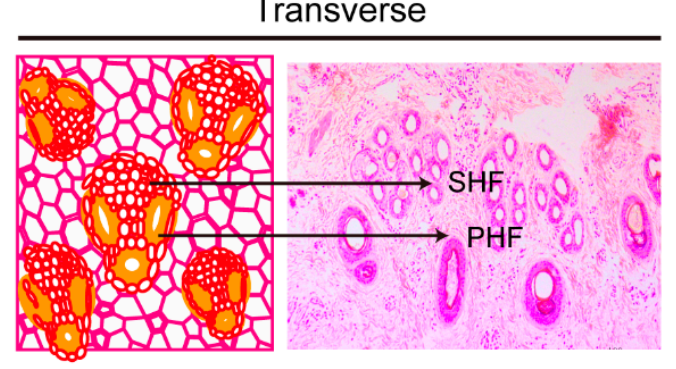

Longitudinal

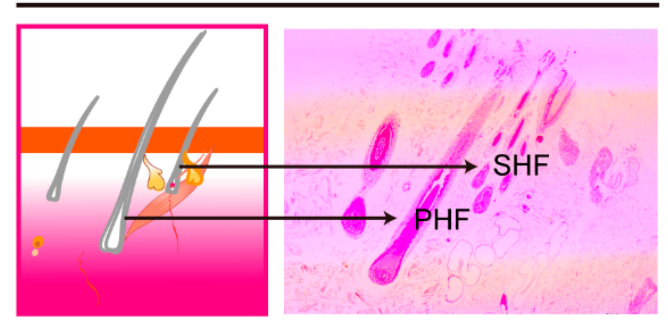

b
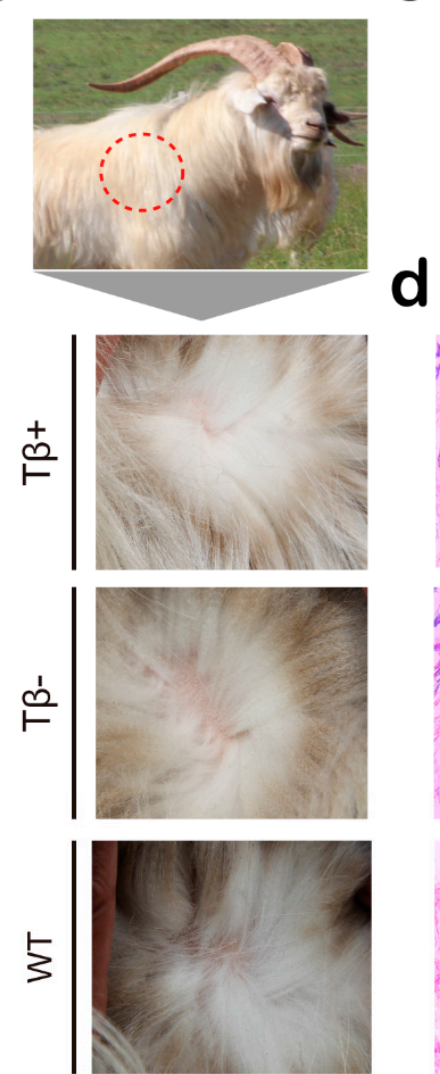

e

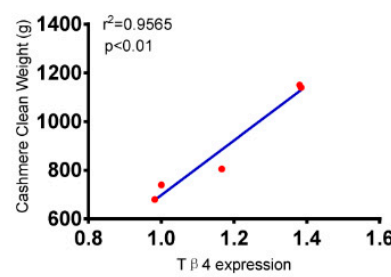

\section{C}

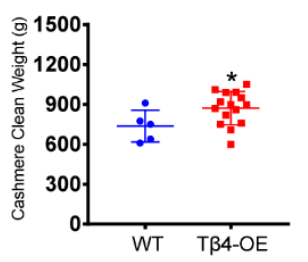

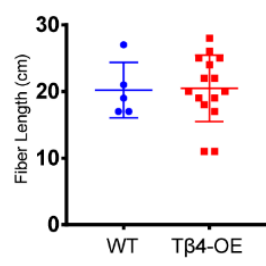
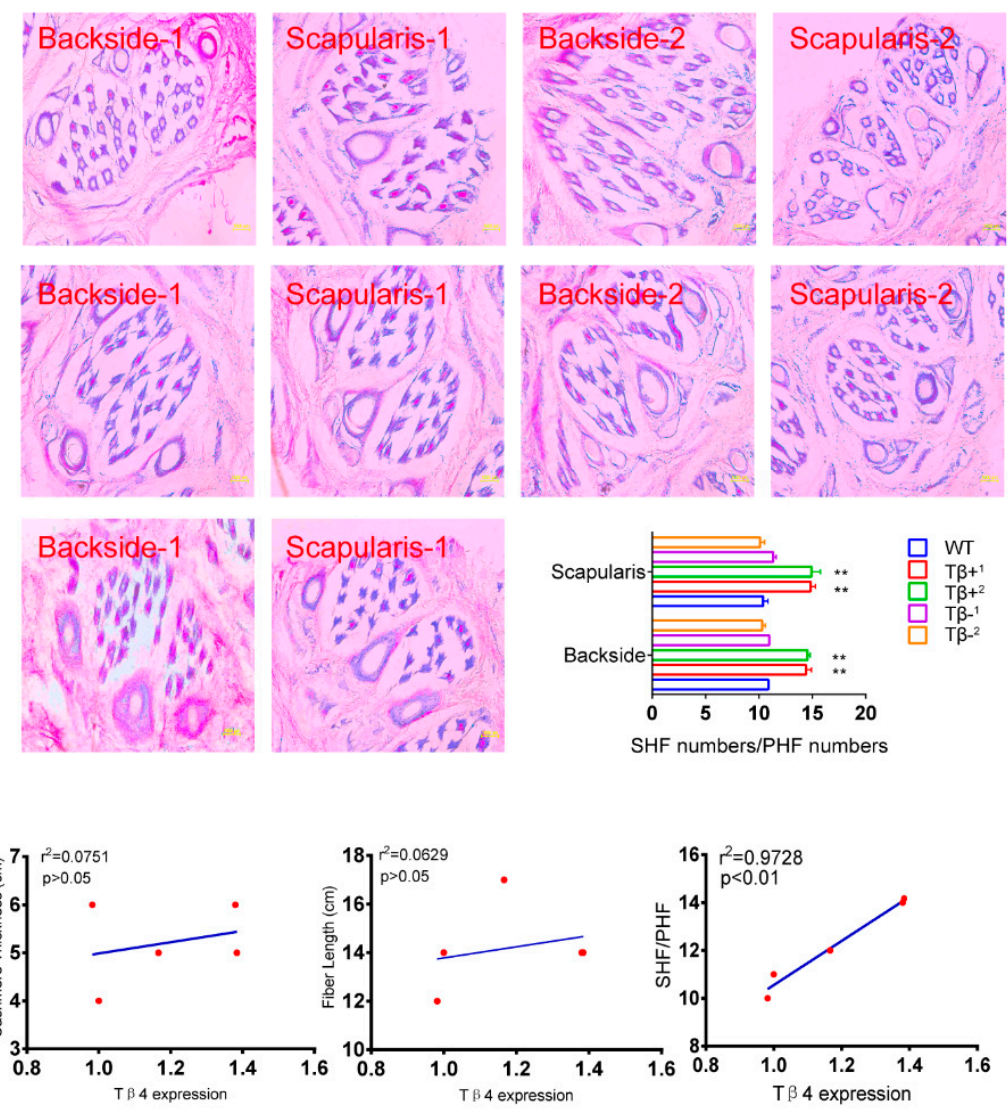

Figure 3. Data showing that the overexpression of $\mathrm{T} \beta 4$ increased secondary hair follicle (SHF) number and cashmere yield. (a) H\&E staining of hair follicle in transverse and longitudinal section. Arrows indicate the primary hair follicle (PHF) and the SHF. (b) Comparison of cashmere growth in different goats. (c) Cashmere clean weight, cashmere thickness, and fiber length in $15 \mathrm{~T} \beta 4$ overexpression (Tß4-OE) and five wild type (WT) goats at two years old $\left({ }^{*} p<0.05\right)$. (d) H\&E staining of backside and scapularis skin from T $\beta 4-\mathrm{OE}$ and WT goats. Scale bar: $100 \mu \mathrm{m}\left({ }^{* *} p<0.01\right)$. (e) The correlation between $\mathrm{T} \beta 4$ expression and cashmere clean weight, cashmere thickness, fiber length, and the cashmere to hair ratio $(\mathrm{SHF} / \mathrm{PHF})$. 


\subsection{T $\beta 4$ May Affect Hair Growth by Interacting with KRT4 to Mediate ERK Signaling Pathway}

To identify DEGs in the skin samples of the T $\beta 4$-OE and WT cashmere goats, we compared the transcriptomes of the three groups and identified 717 DEGs (Figure $4 a, b)$. We next identified the proteins affected by $T \beta 4$ gene expression using co-immunoprecipitation (Co-IP) in combination with mass spectrometry (MS). The proteins were separated with SDS-PAGE electrophoresis, and the protein bands were visualized using Coomassie blue staining. Using MS, we identified 177 proteins that may interact with $\mathrm{T} \beta 4$ (Figure 4c). Five candidate genes were identified by both the transcriptomic and the proteomic analyses: ALBINO3-like protein 1 (ALB), COP9 signalosome complex subunit 3 (CSN3), protein S100-A8 (S100A8), keratin type II cytoskeletal 2 epidermal (KRT2), and keratin type II cytoskeletal 4 (KRT4) (Figure 4d). A KEGG pathway analysis revealed that the DEG were mainly enriched in pathways in arachidonic acid metabolism, linoleic acid metabolism, and nicotine addiction. Meanwhile, the KEGG pathway analysis revealed that the enriched interacting proteins (EIP) were mainly enriched in ribosomes, the biosynthesis of amino acids, and carbon metabolism (Table 2).

Table 2. Comparison of DEG and EIP pathway enrichment analysis.

\begin{tabular}{|c|c|c|c|c|}
\hline Type & Pathway Name & Count & $p$-Value & FDR $^{3}$ \\
\hline \multirow{8}{*}{$\mathrm{DEG}^{1}$} & Arachidonic acid metabolism & 10 & $1.75846 \times 10^{-5}$ & 0.002971802 \\
\hline & Linoleic acid metabolism & 7 & $1.17096 \times 10^{-5}$ & 0.002971802 \\
\hline & Nicotine addiction & 6 & 0.00036797 & 0.024874782 \\
\hline & Steroid hormone biosynthesis & 8 & 0.000307903 & 0.024874782 \\
\hline & Taste transduction & 7 & 0.000363475 & 0.024874782 \\
\hline & Natural killer cell mediated cytotoxicity & 12 & 0.000649358 & 0.034851257 \\
\hline & Neuroactive ligand-receptor interaction & 15 & 0.000721772 & 0.034851257 \\
\hline & Retinol metabolism & 8 & 0.001021739 & 0.043168488 \\
\hline \multirow{5}{*}{$\mathrm{EIP}^{2}$} & Ribosome & 11 & $3.28496 \times 10^{-8}$ & $3.57362 \times 10^{-5}$ \\
\hline & Biosynthesis of amino acids & 7 & $1.12507 \times 10^{-5}$ & 0.012238664 \\
\hline & Carbon metabolism & 8 & $1.23556 \times 10^{-5}$ & 0.013440547 \\
\hline & Glycolysis/Gluconeogenesis & 6 & $8.69038 \times 10^{-5}$ & 0.094499892 \\
\hline & Biosynthesis of antibiotics & 9 & 0.000108387 & 0.117847957 \\
\hline
\end{tabular}

${ }^{1}$ DEG, differentially expressed genes; ${ }^{2}$ EIP, enriched interacting proteins; ${ }^{3}$ FDR, false discovery rate.

A k-means cluster (k-cluster) analysis was then performed to characterize the expression profiles of the 717 DEGs identified in the skin samples. The K-cluster analysis classified all DEGs identified across the T $\beta 4-\mathrm{OE}$ and WT skin samples into six subclusters (Figure 4e). As genes with similar expression patterns are most likely regulated similarly, we compared the subclusters into which each candidate gene fell: ALB was classified in subcluster 3, CSN3 was classified in subcluster 6, S100A8 was classified in subcluster 2, and KRT2 and KRT4 were classified in subcluster 4. KRT2 and KRT4 are KRT homologs, which are well-known fibrous structural proteins found in hair, nails, horns, hooves, wool, feathers, and the outermost epithelial cells. As these proteins may be related to hair follicles, they were examined in further detail. This analysis indicated that the genes in subcluster 4 were primarily associated with cell proliferation, cell growth, and cell differentiation.

The EdU (5-Ethynyl-2'-deoxyuridine) assays showed that cell proliferation increased remarkably after KRT4 was overexpressed in secondary hair follicle dermal papilla cells (SHF-DPCs). However, cell proliferation in the SHF-DPCs was unaffected by KRT2 overexpression (Figure 4f). We also investigated the proliferation-related signaling pathways (i.e., AKT, ERK, and p38) using skin samples from T $\beta 4+$, $\mathrm{T} \beta 4-$, and WT goats. In the T $\beta 4+$ goats, ERK protein expression and phosphorylation levels were significantly higher than those in the WT goat $(p<0.05)$. However, the ERK protein expression and phosphorylation levels in the T $\beta 4$ - goats were not significantly different from those in the WT goat (Figure 4g). 
a

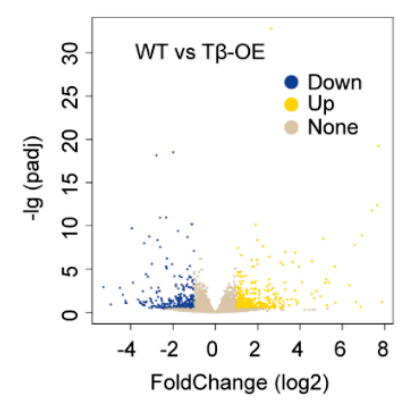

d

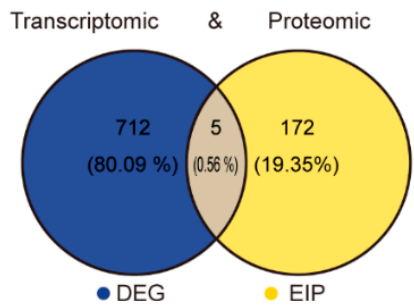

b
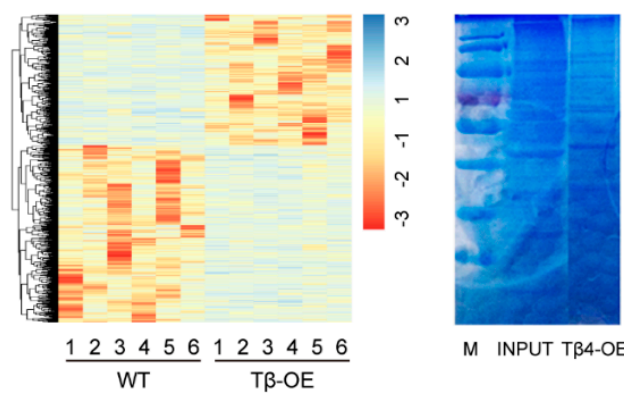

M INPUT TB4-OE EIP

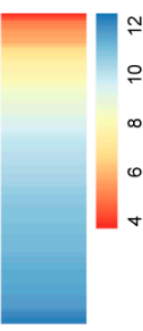

EIP

e

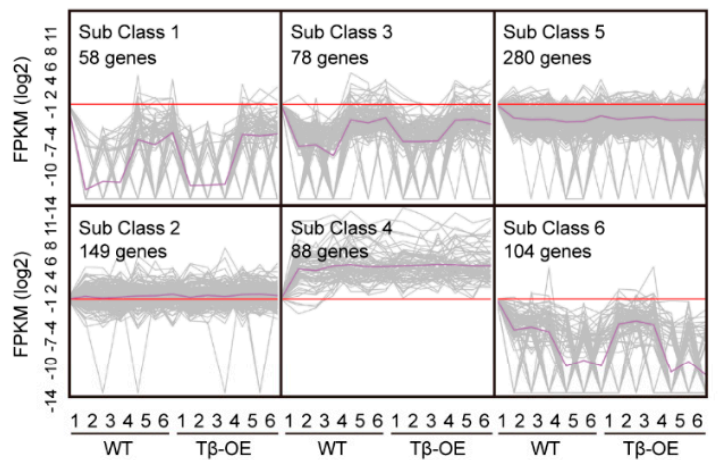

f
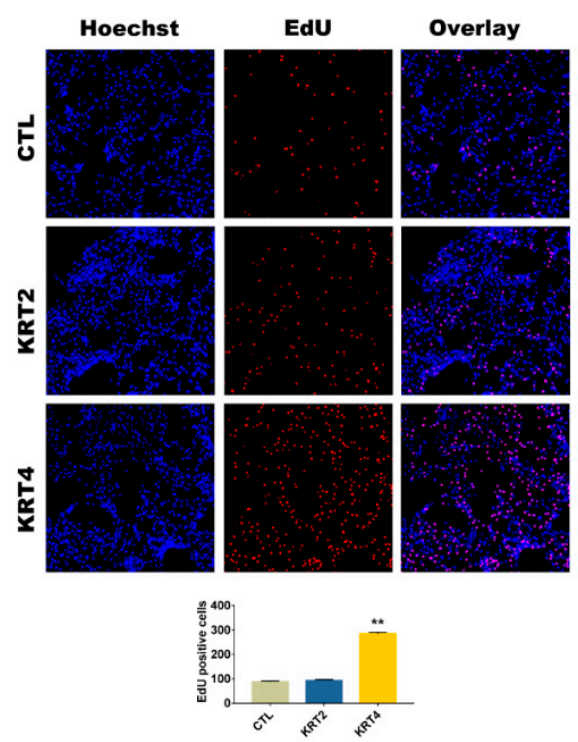

g
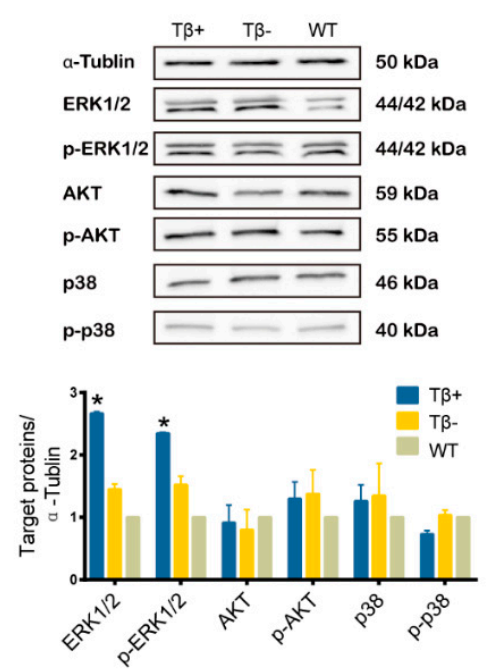

Figure 4. The integrated transcriptomic and proteomic strategy used to investigate the mechanisms underlying the increase in cashmere yield and hair follicle development associated with of $\mathrm{T} \beta 4$. (a) The volcano plot of all genes in the skin samples from the T $\beta 4$ overexpression (T $\beta 4-\mathrm{OE})$ cashmere goats and WT cashmere goats, showing genes with a $>2$-fold difference and an adjusted $p<0.01$ among the groups. (b) The heat map of the gene expression profiles in the skin samples from the T $\beta 4-\mathrm{OE}$ and wild type (WT) cashmere goats. The colored bars illustrate relative expression. In the map, each sample group is clustered. (c) HeLa cells transiently overexpressing $\mathrm{T} \beta 4$ were immunoprecipitated with the anti-T $\beta 4$ antibody for Coomassie Brilliant Blue staining; possible proteins that interact with T $\beta 4$ were identified using mass spectrometry. (d) Venn diagram illustrating the overlap of five genes between the transcriptome-identified DEGs and the proteome-identified enriched interacting proteins (EIP). (e) A cluster analysis of DEGs identified among the skin samples of the T $\beta 4-\mathrm{OE}$ and WT goats and 
functional categorization of the recovered subclusters. (f) Results of the EdU staining assay, showing cell proliferation in secondary hair follicle dermal papilla cells (SHF-DPCs) overexpressing keratin type II cytoskeletal 2 epidermal (KRT2) or keratin type II cytoskeletal 4 (KRT4). Hoechst reagent stains all cell nuclei, while the EdU (5-Ethynyl-2'-deoxyuridine) reagent only stains the newly proliferated cell nuclei $\left.{ }^{* *} p<0.01\right)$. (g) Detection of the proliferation-related signaling pathways in T $\beta 4-\mathrm{OE}$ cashmere goats with significantly improved cashmere yield (T $\beta 4+)$, T $\beta 4-\mathrm{OE}$ cashmere goats with no significant increase in cashmere yield (T $\beta 4-)$, and wild type cashmere goats (WT) $\left({ }^{*} p<0.05\right)$.

\section{Discussion}

The improvement of cashmere yield and quality are two of the goals of cashmere goat breeding. Here, we demonstrated that the overexpression of $\mathrm{T} \beta 4$, which is involved in many critical biological processes, including cell proliferation, cell differentiation, and angiogenesis [39-41], promotes hair follicle development and increased cashmere yield. $\mathrm{T} \beta 4$ stimulates new hair growth by inducing the migration of hair-follicle stem cells [42]. We found that $\mathrm{T} \beta 4$ overexpression led to a relative increase in the number of SHFs (i.e., a greater SHF/PHF ratio), consistent with previous reports that indicated that $\mathrm{T} \beta 4$ overexpression in mouse hair follicles increased hair density [23,24]. Importantly, the T $\beta 4$ transgenic goats were healthy, with normal growth rates, normal activity levels, and no obvious behavioral defects. This suggests that the marker genes such as DsRed and neo we inserted into the genome had no effect on the growth and development of cashmere goats. Thus, despite environmental and experimental challenges, the current method can ensure the safety of transgenic animals. However, the low production efficiency of SCNT is still the bottleneck restricting to its wide application. How to further improve the method should be our focus. In addition, we counted thickness and fiber length to measure cashmere yield. Although they cannot directly affect the cashmere yield, they can indirectly reflect the cashmere yield. These two indexes are also important reference indexes for cashmere quality. Our result suggests that increasing the yield of cashmere did not reduce the quality of cashmere.

In this study, we used the cashmere goat as a model with which to study the effects of T $\beta 4$ on hair follicles in vivo. Five candidate genes were identified by both the transcriptomic and proteomic analyses, and two of these (KRT2 and KRT4) were shown to have similar expression patterns by k-means clustering. As KRT homologs are closely related to hair growth [43-45], we separately overexpressed KRT2 and KRT4 in SHF-DPCs and found that KRT4 increased the growth of SHF-DPCs. In addition, our investigation of proliferation-related signaling pathways showed that the ERK signaling pathway was significantly enhanced in T $\beta 4+$ goats, which is consistent with previous reports that this signaling pathway is involved in the regulation of hair follicle development in a variety of model animals [41,46,47]. This suggested that T $\beta 4$ might bind to KRT4 to mediate the ERK signaling pathway, thereby affecting hair follicle development. This result provides a basis for the study of the molecular mechanisms underlying these effects. In addition, it is always the most important task in the field of animal breeding to breed offspring that can stably inherit the fine traits of their parents. In light of having initially produced $15 \mathrm{~T} \beta 4$ overexpression (T $\beta 4-\mathrm{OE}$ ) cashmere goats, we have successfully established a flock of 23 offspring (six via SCNT and 17 via natural mating (NM). We are also working on studies of genetic stability across generations [48]. However, the desired trait (cashmere yield) exhibited lower fixation in the line-bred offspring compared to the SCNT offspring. It may be due to environmental factors or the organism itself, but part of the randomly integrated T $\beta 4$ of NM offspring underwent methylation modification, leading to a weakened effect on cashmere yield. Our study systematically describes the DNA methylation characteristics between generations of cashmere goats and provides a basis for improving genetic stability.

Genome editing in cashmere goats has many important potential applications with respect to cashmere production. By establishing a $\mathrm{T} \beta 4-\mathrm{OE}$ goat model, we demonstrated that the ectopic expression of $\mathrm{T} \beta 4$ promoted hair follicle development and increased cashmere yield. However, the random genomic integration of foreign genes often results in unstable phenotypes, gene silencing, and unpredictable gene expression patterns $[49,50]$. Here, in some T $\beta 4-\mathrm{OE}$ goats, cashmere yield was not improved (T $\beta 4-)$, indicating that the $\mathrm{T} \beta 4$ did not work. One possible explanation for this 
phenomenon is that, although we integrated $\mathrm{T} \beta 4$ into the genome of the cashmere goat, $\mathrm{T} \beta 4$ was not overexpressed in the hair follicles of the cashmere goats, likely because methylation in the promoter region of the randomly integrated $\mathrm{T} \beta 4$ led to the silencing of $\mathrm{T} \beta 4$ expression [51]. Therefore, it would be more efficient to produce animals carrying exogenous genes integrated at specific genomic loci [52]. Recently developed nuclease-mediated genome editing techniques, such as CRISPR/Cas9, provide precise and efficient methods for the genetic editing of cells, tissues, and whole organisms [53]. It is clear that CRISPR-based genome engineering will accelerate improvements in desirable livestock traits, as this technology allows the precise regulation of a target gene [53-55]. At present, we are integrating CRISPR/Cas9 with SCNT to breed cashmere goats carrying the T $\beta 4$ gene knocked in at specific sites. In this way, we hope not only to precisely regulate the target gene, but also to reduce the effects of gene editing on the genome as a whole. In addition, the use of CRISPR/Cas9 avoids the target gene silencing caused by random integration, which will ensure the stable expression of the target gene and the presence of the target trait in all offspring. In our previous study [10], we successfully obtained a T $\beta 4$ knock-in goat without any screening and fluorescent markers using CRISPR/Cas9 technology. The goat exhibited an increase in cashmere yield by $74.5 \%$ without affecting the fineness and quality. Meanwhile, we have specifically inserted the T $\beta 4$ gene into the goat CCR5 locus which has been suggested as a safe and reliable harbor site for knocking in a foreign gene. Our results have shown that the T 34 CCR5-knock-in goats have no developmental or other abnormalities. In addition, the site can stably express $T \beta 4$ genes without affecting the expression of $T \beta 4$ genes around the integration site.

\section{Conclusions}

In summary, we produced $T \beta 4$ transgenic goats using a tissue-specific overexpression strategy. The $\mathrm{T} \beta 4$-overexpression transgenic goats had increased hair follicle development and higher cashmere yields than the WT goats. The development of this goat model was not only valuable as a framework for future studies of the mechanism of goat follicular development, but also directly led to the improvement of an economically important cashmere goat trait. However, the beneficial effects of ectopic T $\beta 4$ overexpression on cashmere production efficiency and goat physiology must be verified among larger numbers of goats across several different commercial goat breeds.

Supplementary Materials: The following are available online at http://www.mdpi.com/2076-2615/10/1/75/s1, Figure S1: Representative images of $\mathrm{T} \beta 4$ overexpression (T $\beta 4-\mathrm{OE})$ cashmere goat hair follicles stained with anti-T $\beta 4$ and DAPI, Figure S2: Immunofluorescent detection of T $\beta 4$ expression using the T $\beta 4$ antibody, Table S1: List of PCR primer sequences, Table S2: List of qPCR primer sequences, Table S3: Early in vitro development of cloned embryos from different cell lines, Table S4: Statistics on the T $\beta 4$ overexpression (T $\beta 4-\mathrm{OE})$ Embryo of P0, Table S5: Statistics on the T $\beta 4$ overexpression (T $\beta 4-\mathrm{OE})$ Oestrus of P0, Table S6: Statistics on the T $\beta 4$ overexpression (T $\beta 4$-OE) Transfer of P0, Table S7: Statistics on the T $\beta 4$ overexpression (T $\beta 4-\mathrm{OE}$ ) Clonal Goat of P0, Table S8: Statistics on the wild type (WT) Embryo of P0, Table S9: Statistics on the wild type (WT) Oestrus of P0, Table S10: Statistics on the wild type (WT) Transfer of P0, Table S11: Statistics on the wild type (WT) Clonal Goat of P0.

Author Contributions: D.-j.L. conceived and supervised the study, and B.D., H.L., D.-d.G., Z.-w.B., J.-l.Y., Y.J., and L.H. designed and performed the experiments. X.-d.G., M.C., and B.D. analyzed the data and wrote the paper. All authors have read and agreed to the published version of the manuscript.

Funding: This work was supported by the Science and Technology Innovation Guided Project in Inner Mongolia Autonomous Region (KCBJ2018003).

Acknowledgments: We are grateful to the Inner Mongolia YiWei White Cashmere Goat limited liability company for their support with the embryo transfer experiments.

Conflicts of Interest: The authors declare no conflicts of interest.

\section{References}

1. Zeder, M.A.; Hesse, B. The initial domestication of goats (capra hircus) in the zagros mountains 10,000 years ago. Science 2000, 287, 2254-2257. [CrossRef] [PubMed]

2. Bai, W.L. Multivariate statistic analysis of morphological and ecological characters of cashmere goat populations in china. J. Anhui Agric. Sci. 2006, 34, 489. 
3. Xue-Feng, L.V.; Zheng, W.X. Research progress and perspective in skin follicle of cashmere goat. China Anim. Husb. Vet. Med. 2010, 37, 25-28.

4. Bai, J.; Zhang, Q.; Li, J.; Dao, E.J.; Jia, X. Estimates of genetic parameters and genetic trends for production traits of inner mongolian white cashmere goat. Asian-Australas. J. Anim. Sci. 2005, 19, 15-18. [CrossRef]

5. MacHugh, D.E.; Bradley, D.G. Livestock genetic origins: Goats buck the trend. Proc. Natl. Acad. Sci. USA 2001, 98, 5382-5384. [CrossRef] [PubMed]

6. Mao, C.; Xu, Y.; Shi, L.; Guo, S.; Jin, X.; Yan, S.; Shi, B. Effects of photoperiod change on melatonin secretion, immune function and antioxidant status of cashmere goats. Animals (Basel) 2019, 9, 766. [CrossRef]

7. Berger, J.; Buuveibaatar, B.; Mishra, C. Globalization of the cashmere market and the decline of large mammals in central Asia. Conserv. Biol. 2013, 27, 679-689. [CrossRef]

8. Wu, G.; He, Y. Identification of Varieties of Cashmere by Vis/Nir Spectroscopy Technology Based on Pca-Svm; IEEE: Piscataway, NJ, USA, 2009; Volume 29, pp. 1541-1544.

9. Bai, D.P.; Yang, M.M.; Qu, L.; Chen, Y.L. Generation of a transgenic cashmere goat using the piggybac transposition system. Theriogenology 2017, 93, 1-6. [CrossRef]

10. Li, X.; Hao, F.; Hu, X.; Wang, H.; Dai, B.; Wang, X.; Liang, H.; Cang, M.; Liu, D. Generation of tbeta4 knock-in cashmere goat using crispr/cas9. Int. J. Biol. Sci. 2019, 15, 1743-1754. [CrossRef]

11. Zhang, J.; Liu, J.; Yang, W.; Cui, M.; Dai, B.; Dong, Y.; Yang, J.; Zhang, X.; Liu, D.; Liang, H.; et al. Comparison of gene editing efficiencies of crispr/cas9 and talen for generation of mstn knock-out cashmere goats. Theriogenology 2019, 132, 1-11. [CrossRef]

12. Wang, X.; Cai, B.; Zhou, J.; Zhu, H.; Niu, Y.; Ma, B.; Yu, H.; Lei, A.; Yan, H.; Shen, Q.; et al. Disruption of fgf5 in cashmere goats using crispr/cas9 results in more secondary hair follicles and longer fibers. PLoS ONE 2016, 11, e0164640.

13. Ge, W.; Wang, S.H.; Sun, B.; Zhang, Y.L.; Shen, W.; Khatib, H.; Wang, X. Melatonin promotes cashmere goat (capra hircus) secondary hair follicle growth: A view from integrated analysis of long non-coding and coding rnas. Cell Cycle 2018, 17, 1255-1267. [CrossRef] [PubMed]

14. Yang, M.; Song, S.; Dong, K.; Chen, X.; Liu, X.; Rouzi, M.; Zhao, Q.; He, X.; Pu, Y.; Guan, W.; et al. Skin transcriptome reveals the intrinsic molecular mechanisms underlying hair follicle cycling in cashmere goats under natural and shortened photoperiod conditions. Sci. Rep. 2017, 7, 13502. [CrossRef] [PubMed]

15. Dong, Y.; Xie, M.; Jiang, Y.; Xiao, N.; Du, X.; Zhang, W.; Tosser-Klopp, G.; Wang, J.; Yang, S.; Liang, J.; et al. Sequencing and automated whole-genome optical mapping of the genome of a domestic goat (capra hircus). Nat. Biotechnol. 2012, 31, 135-141. [CrossRef]

16. Rile, N.; Liu, Z.; Gao, L.; Qi, J.; Zhao, M.; Xie, Y.; Su, R.; Zhang, Y.; Wang, R.; Li, J.; et al. Expression of vimentin in hair follicle growth cycle of inner mongolian cashmere goats. BMC Genom. 2018, 19, 38. [CrossRef]

17. Stenn, K.S.; Paus, R. Controls of hair follicle cycling. Physiol. Rev. 2001, 81, 449-494. [CrossRef]

18. Bai, W.L.; Dang, Y.L.; Wang, J.J.; Yin, R.H.; Wang, Z.Y.; Zhu, Y.B.; Cong, Y.Y.; Xue, H.L.; Deng, L.; Guo, D.; et al. Molecular characterization, expression and methylation status analysis of bmp4 gene in skin tissue of liaoning cashmere goat during hair follicle cycle. Genetica 2016, 144, 457-467. [CrossRef]

19. Huff, T.; Otto, A.M.; Muller, C.S.; Meier, M.; Hannappel, E. Thymosin beta4 is released from human blood platelets and attached by factor xiiia (transglutaminase) to fibrin and collagen. FASEB J. 2002, 16, 691-696. [CrossRef]

20. Shi, B.; Ding, Q.; He, X.; Zhu, H.; Niu, Y.; Cai, B.; Cai, J.; Lei, A.; Kang, D.; Yan, H.; et al. Tbeta4-overexpression based on the piggybac transposon system in cashmere goats alters hair fiber characteristics. Transgenic Res. 2017, 26, 77-85. [CrossRef]

21. Kumar, N.; Liao, T.D.; Romero, C.A.; Maheshwari, M.; Peterson, E.L.; Carretero, O.A. Thymosin beta4 deficiency exacerbates renal and cardiac injury in angiotensin-ii-induced hypertension. Hypertension 2018, 71, 1133-1142. [CrossRef]

22. Philp, D.; Nguyen, M.; Scheremeta, B.; St-Surin, S.; Villa, A.M.; Orgel, A.; Kleinman, H.K.; Elkin, M. Thymosin beta4 increases hair growth by activation of hair follicle stem cells. FASEB J. 2004, 18, 385-387. [CrossRef] [PubMed]

23. Gao, X.Y.; Hou, F.; Zhang, Z.P.; Nuo, M.T.; Liang, H.; Cang, M.; Wang, Z.G.; Wang, X.; Xu, T.; Yan, L.Y.; et al. Role of thymosin beta 4 in hair growth. Mol. Genet. Genom. 2016, 291, 1639-1646. [CrossRef] [PubMed]

24. Gao, X.; Liang, H.; Hou, F.; Zhang, Z.; Nuo, M.; Guo, X.; Liu, D. Thymosin beta-4 induces mouse hair growth. PLOS ONE 2015, 10, e0130040. [CrossRef] 
25. Hajian, M.; Jafarpour, F.; Aghamiri, S.M.; Rouhollahi Varnosfaderani, S.; Nasr Esfahani, M.H. Effects of ovary storage temperature and embryo vitrification on somatic cell nuclear transfer outcomes in goats. Reprod. Fertil. Dev. 2019. [CrossRef]

26. Burgstaller, J.P.; Brem, G. Aging of cloned animals: A mini-review. Gerontology 2017, 63, 417-425. [CrossRef] [PubMed]

27. Loi, P.; Iuso, D.; Czernik, M.; Ogura, A. A new, dynamic era for somatic cell nuclear transfer? Trends Biotechnol. 2016, 34, 791-797. [CrossRef]

28. Yang, X.; Smith, S.L.; Tian, X.C.; Lewin, H.A.; Renard, J.P.; Wakayama, T. Nuclear reprogramming of cloned embryos and its implications for therapeutic cloning. Nat. Genet. 2007, 39, 295-302. [CrossRef]

29. Matoba, S.; Zhang, Y. Somatic cell nuclear transfer reprogramming: Mechanisms and applications. Cell Stem Cell 2018, 23, 471-485. [CrossRef]

30. Liu, Z.; Cai, Y.; Wang, Y.; Nie, Y.; Zhang, C.; Xu, Y.; Zhang, X.; Lu, Y.; Wang, Z.; Poo, M.; et al. Cloning of macaque monkeys by somatic cell nuclear transfer. Cell 2018, 172, 881-887. [CrossRef]

31. Hao, F.; Yan, W.; Li, X.; Wang, H.; Wang, Y.; Hu, X.; Liu, X.; Liang, H.; Liu, D. Generation of cashmere goats carrying an edar gene mutant using crispr-cas9-mediated genome editing. Int. J. Biol. Sci. 2018, 14, 427-436. [CrossRef]

32. Zhu, B.; Xu, T.; Yuan, J.; Guo, X.; Liu, D. Transcriptome sequencing reveals differences between primary and secondary hair follicle-derived dermal papilla cells of the cashmere goat (capra hircus). PLoS ONE 2013, 8, e76282. [CrossRef] [PubMed]

33. Holm, P.; Booth, P.J.; Schmidt, M.H.; Greve, T.; Callesen, H. High bovine blastocyst development in a static in vitro production system using sofaa medium supplemented with sodium citrate and myo-inositol with or without serum-proteins. Theriogenology 1999, 52, 683-700. [CrossRef]

34. Zhang, J.; Cui, M.L.; Nie, Y.W.; Dai, B.; Li, F.R.; Liu, D.J.; Liang, H.; Cang, M. Crispr/cas9-mediated specific integration of fat- 1 at the goat mstn locus. FEBS J. 2018, 285, 2828-2839. [CrossRef] [PubMed]

35. Siren, J.; Valimaki, N.; Makinen, V. Indexing graphs for path queries with applications in genome research. IEEE/ACM Trans. Comput. Biol. Bioinform. 2014, 11, 375-388. [CrossRef]

36. Wang, L.; Feng, Z.; Wang, X.; Wang, X.; Zhang, X. Degseq: An r package for identifying differentially expressed genes from rna-seq data. Bioinformatics 2010, 26, 136-138. [CrossRef]

37. Wu, H.; Ren, Y.; Pan, W.; Dong, Z.; Cang, M.; Liu, D. The mammalian target of rapamycin signaling pathway regulates myocyte enhancer factor-2c phosphorylation levels through integrin-linked kinase in goat skeletal muscle satellite cells. Cell Biol. Int. 2015, 39, 1264-1273. [CrossRef]

38. Nie, Y.; Liu, D. N-glycosylation is required for fdnc5 stabilization and irisin secretion. Biochem. J. 2017, 474, 3167-3177. [CrossRef]

39. Philp, D.; St-Surin, S.; Cha, H.J.; Moon, H.S.; Kleinman, H.K.; Elkin, M. Thymosin beta 4 induces hair growth via stem cell migration and differentiation. Ann. N. Y. Acad. Sci. 2007, 1112, 95-103. [CrossRef]

40. Lv, S.; Cheng, G.; Zhou, Y.; Xu, G. Thymosin beta4 induces angiogenesis through notch signaling in endothelial cells. Mol. Cell Biochem. 2013, 381, 283-290. [CrossRef]

41. Jeon, B.J.; Yang, Y.; Kyung Shim, S.; Yang, H.M.; Cho, D.; Ik Bang, S. Thymosin beta-4 promotes mesenchymal stem cell proliferation via an interleukin-8-dependent mechanism. Exp. Cell Res. 2013, 319, 2526-2534. [CrossRef]

42. Philp, D.; Goldstein, A.L.; Kleinman, H.K. Thymosin beta4 promotes angiogenesis, wound healing, and hair follicle development. Mech. Ageing Dev. 2004, 125, 113-115. [CrossRef] [PubMed]

43. Agarwal, V.; Panicker, A.G.; Indrakumar, S.; Chatterjee, K. Comparative study of keratin extraction from human hair. Int. J. Biol. Macromol. 2019, 133, 382-390. [CrossRef] [PubMed]

44. Gao, F.; Li, W.; Deng, J.; Kan, J.; Guo, T.; Wang, B.; Hao, S. Recombinant human hair keratin nanoparticles accelerate dermal wound healing. ACS Appl. Mater. Interfaces 2019, 11, 18681-18690. [CrossRef] [PubMed]

45. Wu, Y.L.; Lin, C.W.; Cheng, N.C.; Yang, K.C.; Yu, J. Modulation of keratin in adhesion, proliferation, adipogenic, and osteogenic differentiation of porcine adipose-derived stem cells. J. Biomed. Mater. Res. B Appl. Biomater. 2017, 105, 180-192. [CrossRef]

46. Zhang, J.; Wu, J.; Zeng, W.; Yao, K.; Zu, H.; Zhao, Y. Function of thymosin beta-4 in ethanol-induced microglial activation. Cell Physiol. Biochem. 2016, 38, 2230-2238. [CrossRef] 
47. Chen, Y.; Tian, L.; Yang, F.; Tong, W.; Jia, R.; Zou, Y.; Yin, L.; Li, L.; He, C.; Liang, X.; et al. Tannic acid accelerates cutaneous wound healing in rats via activation of the erk $1 / 2$ signaling pathways. Adv. Wound Care (New Rochelle) 2019, 8, 341-354. [CrossRef]

48. Dai, B.; Zhang, M.; Yuan, J.L.; Ren, L.Q.; Han, X.Y.; Liu, D.J. Integrative analysis of methylation and transcriptional profiles to reveal the genetic stability of cashmere traits in the tbeta4 overexpression of cashmere goats. Animals (Basel) 2019, 9, 1002. [CrossRef]

49. Saito, S.; Maeda, R.; Adachi, N. Dual loss of human polq and lig4 abolishes random integration. Nat. Commun. 2017, 8, 16112. [CrossRef]

50. Iiizumi, S.; Kurosawa, A.; So, S.; Ishii, Y.; Chikaraishi, Y.; Ishii, A.; Koyama, H.; Adachi, N. Impact of non-homologous end-joining deficiency on random and targeted DNA integration: Implications for gene targeting. Nucleic Acids Res. 2008, 36, 6333-6342. [CrossRef]

51. Zhang, G.; Guan, Q.; Chen, G.; Qian, F.; Liang, J. DNA methylation of the cdc211 gene promoter region decreases the expression of the cdk11p58 protein and reduces apoptosis in keloid fibroblasts. Arch. Dermatol. Res. 2018, 310, 107-115. [CrossRef]

52. Capecchi, M.R. Gene targeting in mice: Functional analysis of the mammalian genome for the twenty-first century. Nat. Rev. Genet. 2005, 6, 507-512. [CrossRef] [PubMed]

53. Barrangou, R.; Doudna, J.A. Applications of crispr technologies in research and beyond. Nat. Biotechnol. 2016, 34, 933-941. [CrossRef] [PubMed]

54. Whitworth, K.M.; Rowland, R.R.; Ewen, C.L.; Trible, B.R.; Kerrigan, M.A.; Cino-Ozuna, A.G.; Samuel, M.S.; Lightner, J.E.; McLaren, D.G.; Mileham, A.J.; et al. Gene-edited pigs are protected from porcine reproductive and respiratory syndrome virus. Nat. Biotechnol. 2016, 34, 20-22. [CrossRef] [PubMed]

55. Zheng, Q.; Lin, J.; Huang, J.; Zhang, H.; Zhang, R.; Zhang, X.; Cao, C.; Hambly, C.; Qin, G.; Yao, J.; et al. Reconstitution of ucp1 using crispr/cas9 in the white adipose tissue of pigs decreases fat deposition and improves thermogenic capacity. Proc. Natl. Acad. Sci. USA 2017, 114, E9474-E9482. [CrossRef] [PubMed]

(C) 2019 by the authors. Licensee MDPI, Basel, Switzerland. This article is an open access article distributed under the terms and conditions of the Creative Commons Attribution (CC BY) license (http://creativecommons.org/licenses/by/4.0/). 